\title{
Basal cell carcinoma and squamous cell carcinoma in a single tumor in the anterior auricular area
}

\author{
Il Seok Lee ${ }^{1}$, \\ In Pyo Hong ${ }^{1}$, \\ Hye Kyeong Lee ${ }^{2}$ \\ Departments of ${ }^{1}$ Plastic and \\ Reconstructive Surgery and ${ }^{2}$ Pathology, \\ Eulji University Hospital, Daejeon, \\ Korea
}

\begin{abstract}
The concurrence of basal cell carcinoma (BCC) and squamous cell carcinoma (SCC) in a single tumor is rarely encountered. We report a case of BCC and SCC in a single tumor in the anterior auricular area. A 70-year-old woman had been diagnosed with BCC by a punch biopsy performed at a dermatology clinic. We performed wide excision of the tumor with an ulcer in the anterior auricular area. Analysis of the biopsy specimen revealed the presence of both BCC and SCC in the tumor. This case illustrates that it is necessary to establish a precise diagnosis and formulate appropriate surgical and treatment plans considering the possibility that two carcinomas may coexist, although the possibility is low in patients with skin cancer.
\end{abstract}

Keywords: Basal cell carcinoma / Co-existence / Squamous cell carcinoma

\section{INTRODUCTION}

It is rare for two different types of skin cancers to occur concurrently in the same area [1]. A collision tumor is a combination of two types of tumors in a single lesion [2]. Collision tumors rarely occur in the skin. The malignant-benign tumors of a different origin from the single tumor are the most common type of collision tumors followed by the benign-benign tumors; collision tumors composed of malignant-malignant tumors case are rare [3]. When two types of malignant tumors develop concurrently in the same area, the combination of malignant melanoma and basal cell carcinoma (BCC) is most commonly observed. According to several articles, the prevalence of collision tumors is very low. Especially, the combination of BCC and squamous cell carcinoma (SCC) was rarely found [4]. Here, we report a case of BCC and SCC in a single tumor in the anterior auricular area in a 70-year-old woman detected on histological analysis.

\footnotetext{
Correspondence: In Pyo Hong

Department of Plastic and Reconstructive Surgery, Eulji University Hospital,

95 Dunsanseo-ro, Seo-gu, Daejeon 35233, Korea

E-mail: 20150601@eulji.ac.kr

Received June 18, 2020 / Revised July 28, 2020 / Accepted August 18, 2020
}

\section{CASE REPORT}

A 70-year-old woman presented with a tumor on the left anterior auricular area. the tumor appeared in the left anterior auricular area one month before a visit to the dermatology clinic. The patient was then diagnosed with BCC based on a punch biopsy. She was transferred to our department to undergo excision of BCC. There were no specific findings in the past and family history. A mass was approximately $1.6 \times 1.4 \mathrm{~cm}$ in size, triangular in shape and firmly fixed to the anterior auricular area. The surface of the mass was reddish and there is an ulcer in the center with irregular boundaries (Fig. 1). The patient underwent complete resection with $3 \mathrm{~mm}$ safety margin and primary closure under local anesthesia (Fig. 2). The biopsy of the excised specimens revealed no carcinoma in the resection margin, and both BCC and SCC were diagnosed. On histopathologic examination, typical SCC has nests of squamous epithelial cells arising from the epidermis, extending into the dermis and forming keratin pearls on the left side of the hematoxylin and eosin stained specimen observed under a magnification of $\times 100$. In addition, SCC was well-differentiated and had clear margins. On the right side of the specimen, BCC cells were ob- 


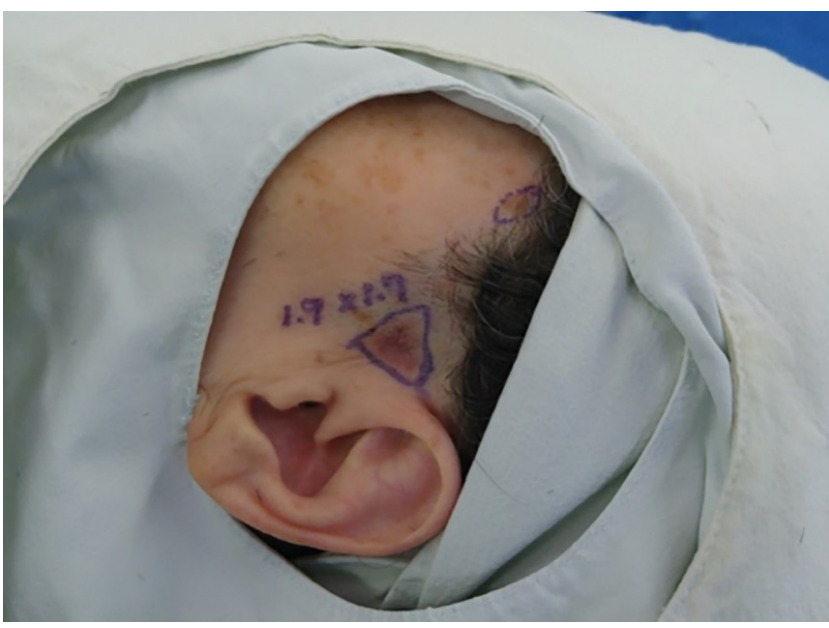

Fig. 1. Preoperative photograph. A solitary mass in the preauricular area in a 70 -year-old woman.

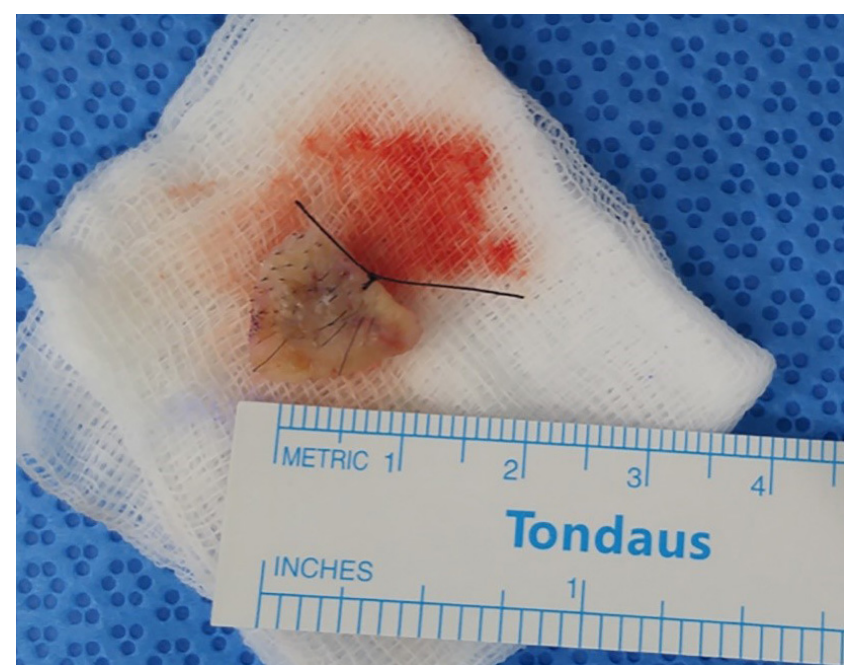

Fig. 2. Intraoperative photograph. The resected specimen measured approximately $1.6 \times 1.4 \times 0.5 \mathrm{~cm}$.

served where basaloid epithelium was clearly separated from SCC and typically formed palisades. These two cell types were clearly separated from each other rather than being observed together in a single tumor cell, as observed in basosquamous carcinoma (Fig. 3). There has been no recurrence or metastasis to date, and we continue to follow-up the patient for 1 year.

\section{DISCUSSION}

A collision tumor is a combination of two types of tumors in a single lesion [2]. The pathogenesis of collision tumors is a matter of speculation [5]. Some authors consider the pathogenesis of collision tumors to be coincidental [6]. Other hypothesis is that one tumor induces epithelial or stromal changes to develop second tumor [7]. Collision tumors rarely occur in the skin.

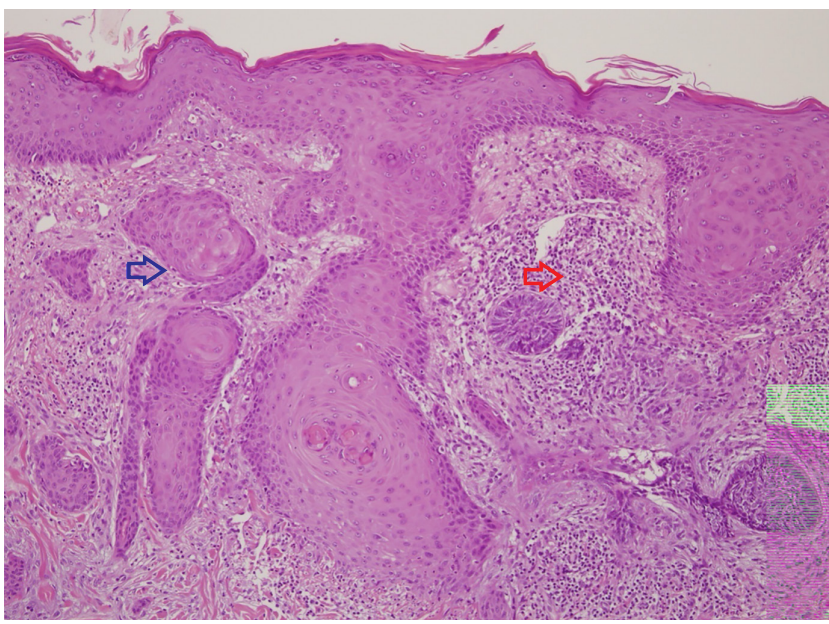

Fig. 3. Photomicrograph of the specimen. The blue arrow shows nests of typical squamous epithelial cells extending to the dermis and forming keratin pearls. The squamous cell carcinoma (SCC) was well-differentiated and had clear margins. The red arrow of the image shows basal cell carcinoma cells where basaloid epithelium was clearly separated from SCC and typically formed palisades. It should be noted that these two cells were clearly separated rather than being observed a tumor composed of two distinct populations of cells that are intermingled, as observed in basosquamous carcinoma $(\mathrm{H} \& \mathrm{E}, \times 100)$.

collision tumors composed of malignant-malignant tumors case are rare [3]. In particular, the BCC and SCC are rare.

In this report, we discuss a rare case of BCC and SCC in a single tumor that was successfully treated by wide excision of the tumor. BCC and SCC in a single lesion are the most common skin cancers observed by plastic surgeons. Although there are some outpatients who visit the clinic directly, most patients present to the plastic surgery department after being diagnosed with skin cancer based on punch biopsy findings at a dermatology clinic. In most cases, a treatment plan is established based on the results of a biopsy. The present case illustrates that two types of skin cancer, BCC and SCC, can occur in a single lesion.

From the viewpoint of a plastic surgeon, the accurate diagnosis of BCC and SCC is important. Accurate and complete treatment according to the type of skin carcinoma is also important. The most familiar and facile technique for the treatment of BCC and SCC is surgical excision. Currently, BCC and SCC differ in terms of recommended excision margins for complete excision. Therefore, it is important to determine surgical treatment following accurate diagnosis of BCC and SCC.

First, with respect to BCC, the goal of the treatment is to perform complete excision by establishing appropriate surgical margins. Although there are some inconsistencies regarding the surgical margins among studies, excision with 3-mm margins is generally recommended for small and well defined primary BCCs [8-13]. According to a study, 2-mm margins are suffi- 
cient in some cases $[11,14]$.

In the case of SCC, surgical excision should include normal skin margins and subcutaneous fat for complete excision $[15,16]$. With respect to the appropriate surgical margins, lowrisk SCCs require 4-mm margins, and high-risk SCCs require 6-mm margins [17].

Other treatments include cryotherapy, electrodesiccation, 5-FU (5-fluorouracil), radiation therapy and Mohs micrographic surgery. The prognosis and treatment of these cases are dictated by the more serious tumor. When diagnosed early and excised with the recommended margins, the prognosis seems to be good as in this patient.

Therefore, it is important to always consider the possibility of composite tumors, carefully perform a punch biopsy of the suspected carcinoma before diagnosis, and obtain frozen sections during surgery to determine appropriate surgical margins according to the biopsy results.

With respect to histologic findings, BCC and SCC were observed as being clearly separate from each other when the specimen was observed at a magnification $\times 100$. However, it is difficult to completely disregard the possibility of SCC differentiating into basosquamous carcinoma where squamous carcinoma cells may be invisible around the basal carcinoma cells. Furthermore, this tumor may be a basosquamous carcinoma, a subtype of BCC, and not a collision tumor. However, the pathologic findings showed that the two types of cancer cells were separated; therefore, it is very unlikely that this was a basosquamous carcinoma.

In conclusion, BCC, SCC, and basosquamous cell carcinoma differ in terms of prognosis, risk of metastasis, and the recommended surgical margins for complete excision; accurate differential diagnosis is necessary, and appropriate treatment and follow-up are needed. Therefore, when determining the diagnosis and surgical treatment of patients with skin cancer, we should not rule out the possibility that BCC and SCC may coexist and that basosquamous cell carcinoma may develop even if patients are referred to plastic surgeons after being diagnosed with BCC and SCC in other hospitals or dermatology clinics.

\section{NOTES}

\section{Conflict of interest}

No potential conflict of interest relevant to this article was reported.

\section{Ethical approval}

The study was approved by the Institutional Review Board of Eulji University Hospital (EMC 2019-12-006-001) and per- formed in accordance with the principles of the Declaration of Helsinki.

\section{Patient consent}

The patient provided written informed consent for the publication and the use of her images.

\section{ORCID}

Il Seok Lee https://orcid.org/0000-0002-8313-2513 In Pyo Hong https://orcid.org/0000-0003-4565-5679

Hye Kyeong Lee https://orcid.org/0000-0003-4967-7816

\section{REFEENCES}

1. Pierard GE, Fazaa B, Henry F, Kamoun MR, Pierard-Franchimont C. Collision of primary malignant neoplasms on the skin: the connection between malignant melanoma and basal cell carcinoma. Dermatology 1997;194:378-9.

2. Inoshita T, Laurain AR, Youngberg GA, Musil G. Metastasis of bronchogenic carcinoma to the skin involved by melanoma. Arch Pathol Lab Med 1984;108:595-8.

3. Boyd AS, Rapini RP. Cutaneous collision tumors: an analysis of 69 cases and review of the literature. Am J Dermatopathol 1994;16:253-7.

4. Hirakawa E, Miki H, Kobayashi S, Nomura Y, Ohmori M. Collision tumor of cutaneous malignant melanoma and basal cell carcinoma. Pathol Res Pract1998;194:649-53.

5. Burkhalter A, White WL. Malignant melanoma in situ colonizing basal cell carcinoma: a simulator of invasive melanoma. Am J Dermatopathol 1997;19:303-7.

6. Bhawan J, Mehregan AH, Jung-Legg Y, Gellis SE. Pigmented basal cell carcinoma and superficial spreading malignant melanoma: an unusual combination. J Cutan Pathol 1984;11:471-5.

7. Brownstein MH, Starink TM. Desmoplastic trichoepithelioma and intradermal nevus: a combined malformation. J Am Acad Dermatol 1987;17:489-92.

8. Kimyai-Asadi A, Alam M, Goldberg LH, Peterson SR, Silapunt $\mathrm{S}$, Jih MH. Efficacy of narrow-margin excision of well-demarcated primary facial basal cell carcinomas. J Am Acad Dermatol 2005;53:464-8.

9. Wolf DJ, Zitelli JA. Surgical margins for basal cell carcinoma. Arch Dermatol 1987;123:340-4.

10. Thomas DJ, King AR, Peat BG. Excision margins for nonmelanotic skin cancer. Plast Reconstr Surg 2003;112:57-63.

11. Bisson MA, Dunkin CS, Suvarna SK, Griffiths RW. Do plastic surgeons resect basal cell carcinomas too widely? A prospective study comparing surgical and histological margins. $\mathrm{Br} \mathrm{J}$ Plast Surg 2002;55:293-7. 
12. Pichardo-Velazquez P, Dominguez-Cherit J, Vega-Memije Ma, Moreno-Coutino G, Proy H. Surgical option for nonmelanoma skin cancer. Int J Dermatol 2004;43:148-50.

13. Wetzig T, Woitek M, Eichhorn K, Simon JC, Paasch U. Surgical excision of basal cell carcinoma with complete margin control: outcome at 5-year follow-up. Dermatology 2010;220:363-9.

14. Kumar P, Watson S, Brain AN, Davenport PJ, McWilliam LJ, Banerjee SS, et al. Incomplete excision of basal cell carcinoma: a prospective multicenter audit. Br J Plast Surg 2002;55:616-22.

15. Goldman GD. Squamous cell cancer: a practical approach. Se- min Cutan Med Surg 1998;17:80-95.

16. Motley R, Kersey P, Lawrence C; British Association of Dermatologists; British Association of Plastic Surgeons; Royal College of Radiologists, Faculty of Clinical Oncology. Multiprofessional guidelines for the management of the patient with primary cutaneous squamous cell carcinoma. Br J Dermatol 2002;146:1825.

17. Brodland DG, Zitelli JA. Surgical margins for excision of primary cutaneous squamous cell carcinoma. J Am Acad Dermatol 1992;27(2 Pt 1):241-8. 